\title{
Significados atribuídos à maternidade por mulheres de um grupo de casais grávidos
}

\author{
Meanings attributed to motherhood by women from a group of pregnant couples
}

Significados atribuidos a la maternidad por mujeres de un grupo de parejas embarazadas

\author{
Isadora Ferrante Boscoli de Oliveira Alves' ${ }^{\circledR}$; Roberta Costal ${ }^{\circledR}$; Margarete Maria de Lima' $\bullet$;

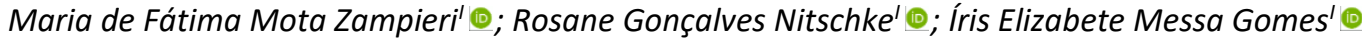

'Universidade Federal de Santa Catarina. Florianópolis, SC, Brasil

\begin{abstract}
RESUMO
Objetivo: conhecer os significados atribuídos à vivência da maternidade por mulheres de um grupo de casais grávido. Método: estudo qualitativo, exploratório-descritivo realizado entre março e agosto de 2018. A coleta ocorreu por meio de observações não-participante, relatos gravados e conversas retiradas do aplicativo WhatsApp. Para análise, adotou-se a proposta operativa de Minayo e o referencial teórico do Interacionismo Simbólico. Resultados: participaram do estudo 23 mulheres que atribuíram à maternidade o significado de amor, cuidado, renúncia, mudanças identitárias, medos e estigmatizações, que afetaram todas as esferas de suas vidas. Considerações finais: os significados atribuídos ao momento afetam o comportamento e bem-estar das mães e representam um elemento de valia às equipes de saúde para a promoção de uma experiência segura. Os espaços educativos dos grupos de casais grávidos se mostraram favoráveis à reflexão e reelaboração dos elementos simbólicos da maternidade e contribuíram para a autonomia e empoderamento das mães.

Descritores: Saúde da Mulher; Maternidade; Educação em Saúde; Grupos de Apoio; Interacionismo Simbólico.
\end{abstract}

\section{ABSTRACT}

Objective: to learn the meanings attributed to the experience of motherhood by women from a group of pregnant couples. Method: in this exploratory, qualitative, descriptive study, conducted between March and August 2018, data were collected by non-participant observation, recorded accounts and WhatsApp conversations. The analysis used Minayo's operative proposal and the theoretical framework of Symbolic Interactionism. Results: the study participants were 23 women, who attributed the meanings of love, care, renunciation, identity change, fear and stigmatization to motherhood; those meanings affected all spheres of their lives. Final remarks: the meanings attributed to the moment affected the mothers' behavior and well-being and represented valuable input to the health teams to arrange a safe experience. Pregnant couples groups proved favorable educational spaces for thinking about, and re-elaborating, the symbolic elements of motherhood, and contributed to the mothers' autonomy and empowerment.

Descriptors: Women's Health; Parenting; Health Education; Self-Help Groups; Symbolic Interactionism.

\section{RESUMEN}

Objetivo: conocer los significados atribuidos a la experiencia de la maternidad por parte de mujeres de un grupo de parejas embarazadas. Método: estudio cualitativo, exploratorio-descriptivo realizado entre marzo y agosto de 2018. La recolección se realizó a través de observaciones no participantes, declaraciones grabadas y conversaciones sacadas de la aplicación WhatsApp. Para el análisis, se adoptó la propuesta operativa de Minayo y el marco teórico del Interaccionismo Simbólico. Resultados: el estudio incluyó a 23 mujeres que atribuyeron a la maternidad el significado del amor, el cuidado, la renuncia, los cambios de identidad, los miedos y las estigmatizaciones que afectaron todas las esferas de su vida. Consideraciones finales: los significados atribuidos al momento afectan el comportamiento y el bienestar de las madres y representan un elemento de valía a los equipos de salud para la promoción de una experiencia segura. Los espacios educativos de los grupos de parejas embarazadas fueron favorables a la reflexión y reelaboración de los elementos simbólicos de la maternidad y contribuyeron a la autonomía y empoderamiento de las madres.

Descriptores: Salud de la Mujer; Responsabilidad Parental; Educación en Salud; Grupos de Autoayuda; Interaccionismo Simbólico.

\section{INTRODUÇÃO}

Tornar-se mãe representa um momento de muitas transformações na vida de uma mulher e envolve um conjunto de fatores bio-psico-comportamentais carregados de valores simbólicos ${ }^{1-6}$. A própria palavra maternidade abrange diferentes significados: pode indicar um estado (ser mãe); uma função reprodutiva (biológica); um estabelecimento que realiza partos (clínicas ou hospitais); uma representação cultural dos poderes maternos; dentre outros, embora sempre assinale uma relação consanguínea ${ }^{7-10}$. Já os valores de amor e cuidado destinados ao bebê estão inseridos no domínio da maternagem, uma escolha de cuidar do infante, que independe de vínculo biológico ou gênero específico ${ }^{8,11}$.

No imaginário de muitas culturas é comum haver a fusão de ambas as abordagens como virtudes sinônimas, exclusivas e inerentes à natureza das mulheres. Entretanto, é preciso relativizá-las à singularidade de cada pessoa, visto

Agradecimentos à Coordenação de Aperfeiçoamento de Pessoal de Nível Superior (CAPES, Brasil), pelo apoio financeiro - Código de Financiamento 001. 
que os ideais altruístas da maternagem, somados às mudanças biológicas da gestação, podem facilmente causar ambiguidades e comprometer a adaptação das mães $1,5,7,8,12,13$.

Nesse sentido, o suporte prestado pelos profissionais de saúde é essencial para que a experiência não assuma uma conotação negativa e coloque um risco a saúde da mãe e a do bebê ${ }^{1,2,5,7,8,12-14}$. No caso do território brasileiro, onde a prevalência de distúrbios psicoemocionais femininos é elevada, a importância do cuidado se torna ainda mais evidente ${ }^{15,16}$.

Conforme os princípios de Promoção da Saúde e do Movimento de Humanização da Assistência Obstétrica, é dever das equipes de saúde realizar um aporte multidimensional às mães e integrar prevenção, tratamento de riscos, rastreio e diagnóstico ao processo educativo, sem comprometer a autonomia e individualidade delas. Para isso, os profissionais precisam identificar como cada mulher experiencia o processo da maternidade e o significa ${ }^{14,15,17-20}$.

Os grupos de gestantes e casais grávidos, enquanto atividades educativas interdisciplinares, são espaços que facilitam a aproximação dos profissionais da população. Ao fornecerem um ambiente acolhedor, favorável a expressão de dúvidas, medos e anseios, esse ambiente coletivo instiga os participantes a compartilharem suas dificuldades e a pensarem, juntos, possíveis soluções. Assim, todos são encorajados a assumirem uma postura protagonista perante o processo e se tornam corresponsáveis por sua saúde ${ }^{14,20-26}$. Embora a estratégia dos grupos esteja em desenvolvimento no Brasil, já foram constatadas as suas contribuições para a saúde materno-infantil, ainda que não tenham sido encontrados estudos que explorassem suas colaborações nos aspectos simbólicos da maternidade ${ }^{18-20,22}$.

Segundo Herbert Mead ${ }^{27}$, criador do Interacionismo Simbólico (IS), as interações sociais são momentos de partilha de símbolos, na qual os envolvidos pensam, preveem, se adaptam e formulam gestos significantes diante de situações especificas. Nela, os seres humanos manipulam os elementos que entram em contato, conforme suas experiências coletivas, ao mesmo tempo em que também são moldados por eles, e se tornam capazes de transformar ativamente a si mesmo, aos outros e a própria realidade, como no caso dos grupos de casais grávidos ${ }^{27-29}$. Diante do exposto, tem-se como objetivo: conhecer os significados atribuídos à vivência da maternidade por mulheres de um grupo de casais grávidos.

\section{MÉTODO}

Pesquisa qualitativa, exploratório-descritiva, guiada pelo referencial teórico do Interacionismo Simbólico (IS) e pelo instrumento do Equator: Consolidated criteria for reporting research (COREQ): a 32-item checklist for interviews and focus groups.

O estudo foi desenvolvido em um grupo de gestante e casais grávidos de uma universidade do sul do Brasil. Tratase de um projeto de extensão multiprofissional, desenvolvido desde 1996, que visa promover estratégias de educação em saúde baseadas nos pressupostos da humanização do cuidado, autonomia e interdisciplinaridade. Seu público-alvo são mulheres com cerca de três meses de gestação e seus acompanhantes ${ }^{21,23,24}$.

Em média, um grupo comporta cerca de 25 gestantes e seus acompanhantes, cuja quantidade variou em cada encontro. Ao total, são realizados oito encontros consecutivos, uma vez por semana, com duração aproximada de três horas no período vespertino.

Todo o conteúdo programático é feito coletivamente de acordo com os temas de interesse das participantes, tais como gestação, parto, amamentação, cuidados com o bebê, puerpério, estrutura física da maternidade, dentre outros; e enviado à um espaço eletrônico, criado no aplicativo Whats $A p p^{\circledR}$. Nesse espaço, também é incentivado a interação entre os membros para a formação de vínculo e compartilhamento de relatos de parto.

Ao final das atividades, um mês após o nascimento do último bebê, é realizado um reencontro. Neste dia, todos os depoimentos fornecidos pelos participantes a respeito de suas experiências são gravados e transcritos por uma bolsista do projeto $21,23,24$.

Todas as participantes recebem no primeiro encontro uma ficha de inscrição contendo informações sociodemográficas (idade, escolaridade, entre outras) e obstétricas (tempo de gestação, quantidade de filhos, informações pré-natal, entre outras); e um Termo de Consentimento Livre e Esclarecido (TCLE). Somente após a assinatura dos documentos que a coleta foi iniciada.

Foi adotado como critérios de inclusão: ser mulher e participar do grupo de gestantes e casais grávidos pesquisado; e de exclusão: apresentar idade igual ou menor a 18 anos. Ao total, participaram do estudo 23 gestantes. Para assegurar os cuidados determinados pelas Diretrizes e Normas Regulamentadoras de Pesquisa Envolvendo Seres Humanos do Conselho Nacional de Saúde ${ }^{30,31}$, a identidade de todas as mulheres foi substituída pela letra M e um número, conforme sua participação (M1, M2, M3...).

Para a coleta dos dados foram realizadas: observação não-participante (O.N.P) dos encontros; análise documental das conversas do WhatsApp ${ }^{\circledR}$ (C.W); e análise dos depoimentos gravados no reencontro (D.G). Também foi proposto, 
no primeiro dia, uma dinâmica de elaboração de cartazes. Nesta atividade, os participantes receberam uma folha de papel kraft, canetas coloridas e foram divididos em quatro grupos. Em seguida, foi dado 15 minutos para que respondessem à pergunta: qual o significado da maternidade para você neste momento? 0 que ela representa em sua vida? Ao final, todos os cartazes foram fotografados e transcritos. A mesma pergunta foi refeita no reencontro e as respostas foram gravadas junto aos depoimentos individuais.

Para a realização das observações não-participantes (O.N.P) foi pré-elaborado um roteiro de observação que visou descrever a caracterização do local e registrar as falas dos participantes (temas de interesse, principais dúvidas, saberes demonstrados, relatos de conflitos ou empoderamento frente a maternidade), bem como a conduta do profissional (abordagem dos temas, condução do grupo, acolhimento dos participantes e das demandas). Os registros foram feitos em um diário de campo no momento da coleta pela pesquisadora principal. Essa pesquisadora já havia acompanhado três grupos anteriores ao estudado para evitar interferir na dinâmica de trabalho ${ }^{32}$.

Dos relatos de WhatsApp ${ }^{\circledR}$, foram coletados apenas as informações referentes ao pós-nascimento até a data do reencontro, incluindo relato de parto, dificuldades/facilidades e exposições emocionais relacionadas a maternidade. Toda a coleta ocorreu no período de março a agosto de 2018.

Para a análise, foi realizado o mapeamento das determinantes do campo (descrição do campo realizada nas O.N.P), a interpretação dos fatos empíricos (registro das falas das participantes feitas na O.N.P; dinâmica de cartazes; C.W; D.G) e o agrupamento dos dados em categorias de sentido, conforme a proposta operativa de Minayo. Em seguida, fez-se a leitura exaustiva dos achados, seguida de uma análise por inflexão e a elaboração do relatório final, com duas categorias, divididas em três subcategorias cada (Figura 1$)^{32}$. Todo o processo foi guiado pelo olhar do interacionismo simbólico.

\begin{tabular}{|l|l|}
\hline Categorias & Subcategorias \\
\hline Maternidade enquanto & -Mudanças biopsicossociais da gestação; \\
processo de transformação & - Despertar do amor materno; \\
feminina & - Desafios e adaptações pós-nascimento: responsabilidade, renúncia e compromisso \\
\hline Nasce uma mãe: & - Eu-mãe; \\
construindo nova & - Eu-mãe-social; \\
identidade & - Eu-mãe-profissional. \\
\hline
\end{tabular}

FIGURA 1: Categorias do estudo e suas respectivas subcategorias. Forianópolis, SC, Brasil, 2018.

Esse estudo foi desenvolvido a partir do macroprojeto intitulado 20 anos do grupo de gestantes e casais grávidos: trajetória histórica, perfil, impacto, percepções e contribuições para os envolvidos, aprovado em maio de 2017, pelo comitê de ética em pesquisa da instituição.

\section{RESULTADOS}

A idade das participantes variou de 19 a 39 anos, havendo predominância da faixa etária entre 26 a 32 anos. Destas, duas eram solteiras, 11 casadas, três estavam em uma união estável e sete não responderam. Para escolaridade, 19 cursavam ou já tinham concluído o ensino superior e quatro, o ensino médio. Em termos religiosos, 10 se identificaram como católicas, duas cristãs e seis não responderam à pergunta.

Quanto as informações gestacionais, 16 mulheres disseram ter planejado a gravidez e sete, não. Delas, 20 eram primigestas e três já tinham filhos. Todas faziam acompanhamento pré-natal, 13 na rede privada, seis na atenção pública e quatro em ambos.

Com relação ao tempo gestacional, houve variação entre 15 e 35 semanas, o que culminou no nascimento de alguns bebês antes do término das atividades. Consequentemente, o volume de participantes nas etapas de coleta foi heterogêneo: 20 estavam na elaboração de cartazes, 19 enviaram seus relatos no WhatsApp ${ }^{\circledR}$ e apenas 10 compareceram ao reencontro. Entretanto, todos os dados foram mantidos, pois muitas mulheres que não compareceram a todos os encontros, ou não puderam estar no reencontro, forneceram seus relatos no WhatsApp ${ }^{\circledR}$.

Para organização dos resultados foi elaborado uma ilustração com as palavras-chave da dinâmica dos cartazes (Figura 2) utilizando o programa Wordart 2018. Essa imagem serviu para nortear a elaboração das categorias do estudo, bem como para comparar o significado atribuído à maternidade antes e após a chegada do bebê. 


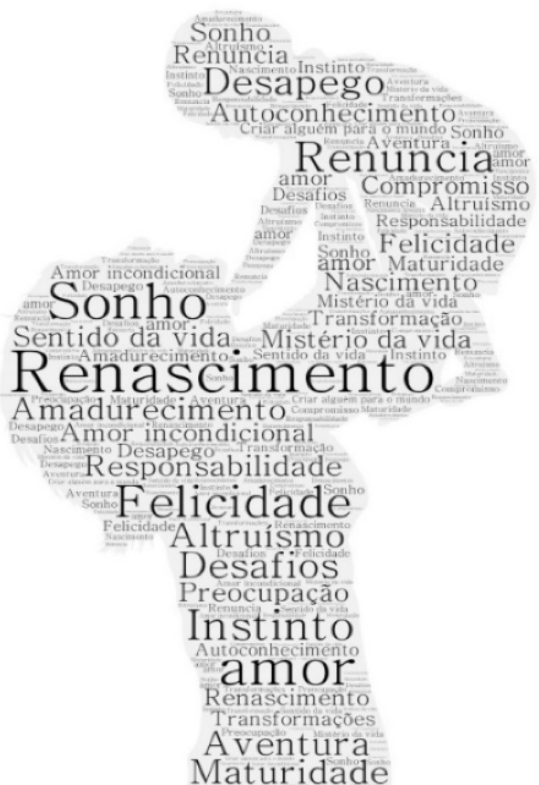

FIGURA 2: Significados prévios atribuídos à maternidade por mulheres de um grupo de gestantes e casais grávidos: atividade de elaboração de cartazes. Florianópolis, SC, Brasil, 2018.

\section{Maternidade enquanto um processo de transformação feminina}

\section{Mudanças biopsicossociais da gestação}

Ao longo dos encontros, as mulheres descreveram as mudanças da gestação e os efeitos gerados ao seu bem-estar.

Para mim é um fenômeno da natureza, como o vento, trovoada. Parece que estou me desintegrando e que só voltarei a estar inteira quando o bebê nascer. Não tenho mais vontade sobre mim, estou apenas reagindo ao que meu corpo está pedindo. M1 (O.N.P)

Pra mim a gestação é feita de fases. Antes ela era de tranquilidade, agora estou na fase da ansiedade. M2 (O.N.P)

É um trabalho diário de aceitação... M3 (O.N.P)

Gravidez não é doença, mas tem sinais de doença sim. É muito desconfortável e não existe muita empatia com o que estamos sentindo [alteração na voz]. M4 (O.N.P)

\section{O despertar do amor materno}

Em seus depoimentos, pré ou pós-nascimento, as participantes atribuíram como elemento de transformação, aprendizado, realização e força, o afeto que desenvolveram para com seus filhos.

Aquela contração vem com cada vez mais intensidade [...]. Muitas pessoas me perguntaram, para que sentir dor? Não é qualquer dor. É dor com significado! A cada contração [...] eu estaria mais próxima de conhecer o maior amor da minha vida! M5 (C.W)

Eu me transformei, claro né...é muito amor. Tudo o que eu tinha assim...de ser irmã mais velha, de cuidar dos irmãos [...] eles vêm comigo. Ah, tú nasceu para ser mãe, agora é de verdade. M6 (D.G)

É um amor que a gente não sabia onde que estava. Parece que já existe a muito tempo [...]. É uma experiência totalmente diferente. A gente se sente mais completa [...]. É o bebê em primeiro lugar [...]. Eu aprendi a ser muito mais forte. $M 7$ (D.G)

Desafios e adaptações pós-nascimento: responsabilidade, renúncia e compromisso

As dificuldades que as mulheres encontram após o parto e as adequações necessárias também foram um fator de impacto à sua vivência.

Eu tive sangramento também... lesão no mamilo (pior que fissura). Estou na oitava sessão de laser! [...] acho que no início a pega estava errada e eu me machuquei muito! Várias vezes achei que não fosse mais capaz de continuar amamentando, ia para o banheiro chorar antes de dar o peito... quase um pânico... M8 (C.W) 
Estamos aprendendo a cada dia. Meu mantra agora é: paciência é uma virtude. M9 (C.W)

A gente acha que ela [bebê] tem alergia a proteína do leite de vaca, então é muito punk porque eu tive que mudar toda a minha alimentação para conseguir deixar ela mais tranquilinha. M10 (D.G)

\section{Nasce uma mãe: construindo uma nova identidade}

\section{Eu-mãe}

Em unanimidade, todas relataram o surgimento de uma nova identidade feminina, papel ainda em fase de ajustamento e aprendizagem.

Por vezes, a mamãe aqui se sente a mulher maravilha, mas daqui dez minutos ela já chora pensando na sua mãe que vai embora, sem saber se vai dar conta de cuidar daquele ser que é totalmente dependente de você! M11 (C.W)

Chegou uma hora que eu falei: preciso sair, eu preciso ser eu, eu não consigo mais ser só a mãe da [nome da bebê]. Nossa, eu lembro [do dia] quando eu entrei no meu carro e olhei no retrovisor e não tinha ninguém [..], eu falei: gente voltei! M12 (D.G)

\section{Eu-mãe-social}

Muitas descreveram a ocorrência de mudanças em suas relações sociais após a chegada do bebê, principalmente envolvendo seu círculo familiar.

Eu não sei se é hormonal ou sei lá, mas eu me vejo como aquele passarinho, o quero-quero. Eu já falei pra elo [sogra], querida eu estou numa fase de quero-quero, tocou no meu filhote.... M12 (D.G)

Para mim mudou o meu olhar no meu relacionamento com ele [companheiro] [...]. Não pra pior, pra melhor [...]. Minha paciência também [...], porque se a gente não tem paciência a gente fica meio louco. Eu não sei, eu não estou conseguindo romantizar muito a maternidade, porque foi muito difícil. M13 (D.G)

Realmente um amor que eu não esperava. A gente vira essa leoa que briga com todo o mundo [...]. Eu, em 15 anos de relacionamento, [...] nunca tinha falado um pouco mais duro com a minha sogra e desde que a [bebê] nasceu... Ela [sogra] inclusive falou pra minha mãe que ela conheceu uma [nome da participante] que ela não conhecia ainda. M14 (D.G)

\section{Eu-mãe-profissional}

Em um dos encontros, a participante M15 trouxe a temática de descriminação com gestantes em ambientes de trabalho, expondo que havia presenciado essa situação durante o processo seletivo do doutorado. Segundo ela, alguns professores estavam barrando a entrada de mulheres, que estivesse ou que pretendessem engravidar durante o período acadêmico, por considerarem que elas teriam uma tendência a faltar as aulas e a prorrogar as bolsas de estudo. Após o seu relato, outras participantes se pronunciaram:

Quando fiquei grávida me senti descriminada no meu trabalho e agora minha imagem profissional foi modificada. M1 (O.N.P)

Tive muita dificuldade de contar para o meu chefe que estava grávida. Demorei um bom tempo para conseguir... [...] nós não deveríamos passar por esse medo. M16 (O.N.P)

Tive muitos conflitos comigo mesma por não estar mais no mesmo ritmo e não produzir tanto quanto antes. Isso me gerou um stress muito grande! M17 (O.N.P)

Ninguém consegue trabalho estando grávida. M18 (O.N.P)

M1, quando deu seu depoimento, contou que algumas semanas antes de começar a frequentar o grupo precisou faltar um dia de trabalho por questões de saúde, que não estavam ligadas a gestação. Após esse episódio, seu supervisor a retirou de suas funções por concluir que as faltas se tornariam recorrentes. Ela também referiu que, diversas vezes, recebeu indiretas do chefe na forma de elogios à outras mulheres, que haviam voltado ao trabalho antes do término da licença à maternidade.

\section{DISCUSSÃO}

Na primeira subcategoria, mudanças biopsicossociais da gestação, nota-se que as alterações vividas no período gravídico foram amplas e ocasionaram desconfortos físicos (M4), emocionais (M2), psíquicos (M3) e identitários (M1) às participantes.

As variações bruscas do período, além de gerarem sintomas como náusea, fraqueza, dores abdominais, dispneia, lombalgia, dentre outros e afetarem a disposição física (observado na fala de $\mathrm{M} 4)^{19}$ e emocional das mulheres (fala de M2), também as limitam no controle de seus corpos, causando-lhes a sensação de estarem perdendo sua identidade (como ilustra a desintegração de M1) ${ }^{19,33,34}$. O próprio Ministério da Saúde (MS) reconhece o processo como uma preparação para 
uma nova fase de vida, propício à adoção de mudanças e à reflexão do significados atribuído ao ser mulher, mas que exige um trabalho diário de aceitação (fala de $M 3)^{5,6,21,34}$. Para o olhar interacionista, esse movimento de adequação das mães às auxiliam a assimilarem as atitudes, gestos e símbolos pertencentes ao fenômeno da maternidade de seu contexto, de modo que possam se reconhecer e, ao mesmo tempo, serem reconhecidas pelo coletivo ${ }^{35}$.

A dinâmica entre as mães e o meio social fica mais evidente nas subcategorias, despertar do amor materno e desafios e adaptações pós-nascimento. Em ambos os casos, o sentimento de amor descrito nos depoimentos das participantes apareceu como elemento intrínseco à maternidade (fala M6) e o principal responsável pelo enfrentamento das dificuldades (fala M5, M6, M7).

A esse respeito, a historiadora francesa, Badinter ${ }^{36}$, afirma que a naturalização do amor materno, vinculado a esfera do cuidado, não existia até meados da idade média. A autora não nega a existência do sentimento de amor entre mães e filhos antes desse período, apenas o evidencia enquanto valor social, incitado pelos poderes estatais da Europa, no intuito de garantir o aumento populacional e a manutenção das riquezas. Segundo ela, as mulheres se tornaram as responsáveis pela sobrevivência das crianças por terem a capacidade de se procriar, logo, para as ordens religiosas e cientificas da época, estariam naturalmente aptas a exercer a função (observado na fala de M6) ${ }^{3,9,11,36}$.

Pela influência colonialista da Europa na história do Brasil, a mesma visão do feminino ainda perpetua nos dias atuais $^{11}$. A caderneta da gestante, por exemplo, afirma que as mães crescem enquanto mulheres durante a gestação e desenvolvem a confiança necessária para cuidar do bebê ${ }^{34}$. No caso das participantes, o valor do amor, de fato, assumiu a forma simbólica de um senso de compromisso para com o bem-estar dos bebês, chegando ao ponto de as mães desconsiderarem as próprias necessidades, independentemente de serem físicas (como a lesão no mamilo de M8), psíquicas (a paciência de M9) ou comportamentais (as adequações alimentares de M10).

Segundo autores, a renúncia em prol dos filhos é característica no estereótipo da mulher moderna que, por muitos anos, semeou o valor da vigilância entre as mães ${ }^{4,6,33}$. A falha do cuidado era motivo de vergonha e sinalizava negligência materna ${ }^{36}$.

Esse tipo de associação, para IS, demonstra o impulso que forma os fenômenos sociais de um contexto e os sentimentos caros aos indivíduos que o compõem. Ao serem compartilhados e propagados entre os interlocutores os símbolos ganham força no corpo coletivo, que garantem a sua incorporação e permanência ${ }^{4-6,28,37}$. Entretanto, na segunda categoria, nasce uma mãe: construindo uma nova identidade, foi possível identificar como a incorporação desses valores afetou a subjetividade das integrantes, fosse pelo aflorar de sentimentos ambíguos (relatados por M11) ou pela necessidade de auto-reconhecimento (M12).

Alguns autores concordam que o tornar-se mãe e desenvolver as funções maternas são coisas distintas e envolvem múltiplos fatores, não necessariamente só o puro instinto ${ }^{1,6,33}$. Muito embora, na subcategoria eu-mãe-social, a questão do instinto maternal tenha repercutido nas relações interpessoais das participantes, fosse em conflitos com a sogra (M12, M4), ou no relacionamento com o companheiro (M13). Para ilustrar essas mudanças, as integrantes recorreram a figuras de animais, como a leoa e o quero-quero, simbolizando o desejo natural de proteger os filhos.

Alguns estudos vinculam esse impulso de proteção materna à ocorrência da chamada melancolia da maternidade ou baby blues, uma condição hormonal transitória que acomete 70 a $90 \%$ das mulheres após o parto. A alteração causa uma hipersensibilidade nas mães para as necessidades do bebê e, segundo a psicanálise, é a responsável pela formação do vínculo entre ambos ${ }^{1,2,38}$.

No caso da participante M14, que afirmou não conseguir romantizar a maternidade por ter sido uma experiência difícil, o significado dado ao fenômeno adquiriu outra interpretação. De acordo com o IS, por não conseguir se adaptar, a participante passou a operar fora das regras pré-determinadas pelo coletivo, criando um novo contexto para si. Ao incluir o valor da paciência, ela reelaborou os determinantes da maternidade que existiam à realidade do casal, afetando positivamente o relacionamento $27-29$.

A mesma adaptação não foi observada na última subcategoria, eu-mãe-profissional, onde foi constatado tensão entre papéis distintos, que causou às mães sentimentos de medo, stress, culpa e sensação de discriminação (relato de M1, M15 e M18). Pontos similares são encontrados em outros estudos feitos no Brasil, na qual foi identificado que as mães têm mais chances de terem os cargos modificados ou perderem oportunidades de trabalho, chegando ao ponto de elas omitirem os filhos em entrevistas de emprego 39,40

A atitude irracional destinada a elas em ambientes de trabalho é um reflexo da dualidade criada no século $X X$, quando a realidade econômica do Brasil obrigou as mulheres a saírem do espaço de seus lares para buscarem melhores condições financeiras. Ao impedir que alcançassem a máxima de seus papéis maternos, a situação lançou sobre elas uma dupla cobrança: serem mães imaculadas e profissionais competentes, muitas vezes obrigando-as a escolherem entre uma função ou outra ${ }^{39,40}$. O tema, como observado, ainda é origem de angústia e preocupação entre elas que, desde então, lutam para conciliar ambas, enquanto enfrentam assédio, sexismo, opressão e silenciamento ${ }^{24-26,39,40}$. 


\section{Limitações do estudo}

Como limitações do estudo, destaca-se o volume de dados coletados e amplitude do tema, que não se esgotam ao recorte desse estudo. Sugere-se, portanto, que outras pesquisas sejam feitas, contemplando períodos, perfis e realidades sociais diferentes para comparação.

\section{CONSIDERAÇÕES FINAIS}

O significado atribuído à maternidade pelas participantes ganhou conotação de amor, cuidado incondicional, sentido de vida, responsabilidades, perda de autonomia, renúncias, medo e estigma; e afetou todas as áreas de suas vidas.

O arcabouço simbólico do período, por carregar o bojo histórico-cultural onde as mães estão inseridas, se mostrou complexo e com poder de afetar a forma como elas agem. De igual modo, os mesmos elementos tornaram-se facilitadores do processo de adaptação, quando relativizados às suas vivencias individuais.

Os grupos de casais grávidos contribuíram a esta investigação como um espaço educativo-reflexivo da construção simbólica da maternidade, um instrumento terapêutico de baixo custo, fácil implementação que precisa ser mais estudado.

\section{REFERÊNCIAS}

1. Oliveira MAC, Marques SS. Contributions to a Critical Reconstruction of The Modern Grammar of Motherhood. Rev. Estud. Fem. [Internet]. 2020 [cited 2020 Aug 5]; 28 (1):1-16. DOI: https://doi.org/10.1590/1806-9584-2020v28n168037.

2. Santos FAPS, Mazzo MHSN, Brito RS. Feelings experienced by recent mothers during the postpartum. Rev. Enferm. UFPE on line [Internet]. 2015; 9(Suppl 2):858-63. DOI: https://periodicos.ufpe.br/revistas/revistaenfermagem/article/download/10410/11185.

3. Tomaschewski-barlem JG, Bordignon SS, Costas CFS, Costas CO, Barlem ELD. Promoting self-esteem during pregnancy: focus on user embracement. Enferm. Foco [Internet]. 2016 [cited 2019 Mar 19]; 7(2):83-6. Available from: http://revista.cofen.gov.br/index.php/enfermagem/article/view/801/326.

4. Chae J. "Am I a better mother than you?" media and 21 st-century motherhood in the contexto of the social comparison theory. Sage Open [Internet]. 20152016 [cited 2019 Mar 19]; 42(4):503-25. DOI: https://doi.org/10.1177/0093650214534969.

5. Donath O. Regretting motherhood: a sociopolitical analysis. Signs [Internet]. 20152016 [cited 2019 Mar 19]; 40(2 Winter):34367. DOI: https://doi.org/10.1086/678145.

6. Laney E.K, Hall MEL, Anderson TL, Willingham MM. Becoming a mother: the influence of motherhood on woman's identity development. Identity [Internet]. 20152016 [cited 2019 Mar 19]; 15:126-45. DOI: https://doi.org/10.1080/15283488.2015.1023440.

7. Machado JSA, Penna CMM, Caleiro RCL. Cinderella's shoe: maternity, no materniry, and parenting in stories told by woman. Saúde debate [Internet]. 2019 [cited 2020 Nov 18]; 43(123):1120-31. DOI: https://doi.org/10.1590/0103-1104201912311.

8. Lopes ARS, Carvalho AS. Becoming Mother: considerations about maternity place nowadays. Rev. FSA [Internet]. 2017 [cited 2020 Nov 18]; 14(2):146-70. DOI: https://doi.org/10.12819/2017.14.2.9.

9. Resende DK. Maternity: a historical and social construction. Rev. Pretextos. Psicol [Internet]. 2017 [cited 2018 Sep 27]; 2(4):17591. Available from: http://periodicos.pucminas.br/index.php/pretextos/article/view/15251.

10. Mendonça MC, editor. Key research findings of the doctoral project: Motherhood in Advertising. A Qualitative and Semiotic Analysis in Sao Paulo and Toronto. Seminário internacional fazendo gênero 11 \& 13 wom's words congresso; 2017; Florianópolis: [Internet] 2017 [cited 2018 Apr 9]. 13 p. Available from: http://www.en.wwc2017.eventos.dype.com.br/resources/anais/1499102125_ARQUIVO_MaternidadenaPublicidade_Mendonc a_MariaCollierde_2017_Texto_completoMM_FG.pdf.

11. Lanzetta RC, Bittencourt MIGF. Purchased support: contemporary assistance for motherhood. Rev. Polemoca [Internet]. 2016 [cited 2018 Apr 9]; 16(1):1-13. DOI: https://doi.org/10.12957/polemica.2016.21339.

12. Tomaz R. Feminism, motherhood and the media - historically close relations in review. Galáxia [Internet]. 2015 [cited 2018 Apr 9]; 29:155-66. DOI: https://doi.org/10.1590/1982-25542015120031.

13. Porto RA, Maranhão TLG, Félix WM. Psychosocial Aspects of Postpartum Depression: a Systematic Review. Id on line [Internet]. 2017 [cited 2018 Apr 9]; 11(34):219-45. DOI: https://doi.org/10.14295/idonline.v11i34.686.

14. Camillo BS et al. Health education actions in primary attention to pregnant and puerperal woman: integrative review. JNUOL [Internet]. 2016 [cited 2018 Apr 9]; 10(sup 6):4894-901. DOI: https://doi.org/10.5205/1981-8963-v10i6a11270p4894-49012016.

15. Theme MMF, Ayers S, Gama SG, Leal MC. Factors associated with postpartum depressive symptomatology in Brazil: the birth in Brazil National Research Study, 2011/2012. J Affect Disord [Internet]. 2016 [cited 2018 Apr 9]; 194:159-67. DOI: https://doi.org/10.1016/j.jad.2016.01.020.

16. Arrais AR, Araujo TCCF, Schiavo RA. Depressão e ansiedade gestacional relacionadas à depressão pós-parto e o papel preventivo do pré-natal psicológico. Rev. Psicol. Saúde [Internet]. 2019 [cited 2020 Nov 13]; 11(2):23-34. DOI: https://doi.org/10.20435/pssa.v0i0.706.

17. Barreto CN et al. "The Unified Health System that works": actions of humanization of prenatal care. Rev. Gaúcha. Enferm. [Internet]. 2015 [cited 2020 Nov 13]; 36(esp):168-79. DOI: https://doi.org/10.1590/1983-1447.2015.esp.56769. 
18. Organização mundial da saúde. OMS publica novas orientações sobre pré-natal para reduzir mortes de mães e bebês [Internet]. Organização das Nações Unidas do Brasil, 2016 [cited 2017 Apr 20]. Available from: https://nacoesunidas.org/oms-publicanovas-orientacoes-sobre-pre-natal-para-reduzir-mortes-de-maes-e-bebes/.

19. Lemos EF. Cuidando da saúde da mulher: rotinas de pré-natal e ginecologia. 1aed. Florianópolis: Editograf; 2017. $204 \mathrm{p}$

20. Ministério da Saúde (BR). Manual de acolhimento e classificação de risco em obstetrícia. Brasília: Secretaria de Atenção à Saúde; 2017.

21. Zampieri MF, Grégorio VRP, Custódio ZAO, Regis MI, Lima MM, Costa R. 20 anos do grupo de gestantes e casais grávidos: trajetória histórica, perfil, impacto, percepções e contribuições para os envolvidos. Florianópolis: UFSC; 2016 [cited 2017 Apr 20]. 38 p. Available from: https://repositorio.ufsc.br/handle/123456789/212357.

22. Teixeira FV, Linhares AEP, Guimarães RX, Cavalcante MMB, Lopes AIN, Teixeira MA. Educational workshops for a group of pregnant women about the gravidic period. Sanare [Internet]. 2016 [cited 2018 Oct 30]; 15(1):119-25. Available from: https://sanare.emnuvens.com.br/sanare/article/view/937/566.

23. Lima MM, Machado ML, Costas R, Canever B, Alves IFBO. Contribution of university extension activities in a group of pregnant women and couples for the training of nurses. Esc. Anna Nery [Internet]. 2018 [cited 2018 Oct 30]; 22(4):1-8. DOI: https://doi.org/10.1590/2177-9465-EAN-2017-0367.

24. Rovaris M.L, Gelbcke FL, Sila RM, Portella PP. Atenção à saúde da mulher e do recém-nascido: manual de boas práticas. 1 ed. Ebserh: UFSC, 2018 [cited 2018 Oct 30]. Available from: http://www2.ebserh.gov.br/documents/2016343/3547298/final.pdf/3ac08f66-68e3-41ff-a569-1f1c118e71ba.

25. Queiroz LS, Cerqueira CO, Mendonça AVM. Implementation of a group of pregnant adolescents: reports of information, education and communication for the health promotion]. Tempus [Internet]. 2015 [cited 2018 Oct 30]; 9(1):145-53. DOI: https://doi.org/10.18569/tempus.v9i1.1698.

26. Vieira AN, Padilha MI, Costa R, Gregório VRP, Silva AR. Group of pregnant women and / or pregnant couples: a collective construction process (1996-2016). Rev. Anna Nery [Internet]. 2019 [cited 2018 Oct 30]; 23(2):1-8. DOI: https://doi.org/10.1590/2177-9465-ean-2018-0221.

27. Blumer $\mathrm{H}$. The nature of simbolic interacionism. In: Mortensen CD. Communication theory: second edition. London: Trasaction Puplishers; 2014. P. 102-121.

28. Bruno T, Alves M, Ferreira FV. Symbolic Interactionism as a theoretical and methodological tool for the study of Cyberculture. Rev. Razón y palabra [Internet]. 2017 [cited 2018 Aug 20]; 21(1):456-75. Available from: http://www.redalyc.org/html/1995/199551160024/.

29. Dalbosco CA, Maraschin R. Thinking the education at post-metaphysical times: the alternative of symbolic interactionism. Educação UFSM [Internet]. 2017 [cited 2018 Aug 20]; 42(3):629-42. DOI: https://doi.org/10.5902/1984644424140.

30. Conselho Nacional de Saúde (Br). Diretrizes regulamentadoras de pesquisas envolvendo seres humanos. Resolução n. 466, de dezembro de 2012.

31. Conselho Nacional de Saúde (Br). Princípios éticos das pesquisas em ciências humanas e sociais. Resolução n. 510, de dezembro de 2016.

32. Minayo MCS. O desafio do conhecimento. 14.ed. São Paulo: Hucitec, 2014.

33. Fox B, Neiterman E. Embodied motherhood: woman's feeling about their postpartum bodies. Gend. Soc. [Internet]. 2015 [cited 2018 Aug 20]; 29(5):670-93. DOI: https://doi.org/10.1177/0891243215591598.

34. Ministério da Saúde (Br). Caderneta da Gestante. Ed. Eletrônica. Brasília: Ministério da Saúde; 2018 [cited 2018 Aug 20]. Available from: https://portalarquivos2.saude.gov.br/images/pdf/2018/agosto/31/Caderneta-da-Gestante-2018.pdf.

35. Casagrande CA. Symbolic interactionism, the formation of the self and education: some approaches to G. H. Mead's thinking. Rev. Educ. Filosof. [Internet]. 2016 [cited 2018 Aug 20]; 30(59):375-403. DOI: https://doi.org/10.14393/REVEDFIL.issn.01026801.v30n59a2016-p375a403.

36. Badinter E. Um amor conquistado: o mito do amor materno. Rio de Janeiro: Nova Fronteira, 1985. 268 p.

37. Muniz JO, Veneroso CZ. Differences in Labour Force Participation and Wage Gaps by Gender and Income Classes: an Investigation of the Motherhood Penalty in Brazil Inequalities. Dados rev. ciênc. sociais [Internet]. 2019 [cited 2020 Mar 26]; 62(1):1-38. DOI: https://doi.org/10.1590/001152582019169.

38. Silva HC, Silva MR, Frizzo GB, Donelli TMS. Psychofunctional Symptoms and Maternal Depression: A Qualitative Study. Psico-USF [Internet]. 2018 [cited 2020 Mar 26]; 23(1):59-70. DOI: https://doi.org/10.1590/1413-82712018230106.

39. Moreira JR, Perrini P, Ribeiro JBP. Mãos trabalhadoras do sol nascente: impressões sobre a relação entre maternidade, trabalho e políticas públicas. Projeção, Direito e Sociedade [Internet]. 2016 [cited 2018 Oct 3]; 7(2):26-52. Available from: http://revista.faculdadeprojecao.edu.br/index.php/Projecao2/article/view/729/641.

40. Cavalcanti NCSB, Baía DCP. Being mother in world of work: notes about the challenges of reinsertion of women in the market of work after the experience of maternity. Seminário internacional fazendo gênero 11 \& 13 woman's words congresso; 2017; Florianópolis [Internet] 2017 [cited 2018 Oct 13]; 26-52. Available from: http://www.en.wwc2017.eventos.dype.com.br/resources/anais/1499457316_ARQUIVO_Sermaenomundodotrabalho.pdf. 